\title{
EEN BRIEF VAN ANQUETIL DU PERRON,
}

\author{
MEDEGEDEELD DOOR
}

Dr. H. KER N.

In deze Bijdragen, D. XXXVII, blz. 145, heeft Prof. Houtsma eenen brief van den vermaarden Anquetil du Perron, gedagteekend 23 Febr. 1790 , openbaar gemaakt. Het was hem onbekend dat het door hem medegedeelde schrijven slechts een gedeelte bevatte van eenen brief, die door Anquetil du Perron gericht was aan den Heer A. G. Camper te Klein-Lancum. Wat Houtsma gevonden had en in de Bijdragen openbaar maakte, was slechts een afschrift, door Pluygers genomen, en bevatte alleen dat gedeelte, hetwelk betrekking had op de uit Malabar afkomstige koperplaten, die thans in de Leidsche Boekerij bewaard worden. Eerst onlangs heeft Dr. H. G. Hamaker mij verrast met de mededeeling, dat de oorspronkelijke brief van Anquetil du Perron nog aanwezig is. Hij heeft mij dien welwillend ter hand gesteld en daaraan is het te danken dat ik hier inzage kan geven van 't oorspronkelijke van den nog onbekenden, in vele opzichten belangrijken inhoud. Alvorens echter tot de mededeeling van dien brief over te gaan, zal ik eenige mij door Dr. Hamaker verstrekte inlichtingen mededeelen. Hij schrijft mij het volgende:

"Florentius Camper is van 1702 tot 1713 predikant in Indië geweest, laatstelijk te Batavia. In dit jaar is hij naar Holland teruggekeerd en heeft toen de bekende twee koperen boeken medegebracht, die tot den dood van A. G. Camper in 1820 in het bezit van die familie gebleven zijn. Daarna zijn zij het eigendom geworden van den hoogleeraar H. A. Hamaker, die met Johanna, de oudste dochter van A. G. Camper gehuwd was. Na den dood van H. A. Hamaker in 1835 zijn zij in het bezit gebleven zijner kinderen, tot deze in 1862 gezamenlijk besloten dien schat aan de Bibliotheek der Ireidsche Hoogeschool te schenken. Bij die gelegenheid 
heb ik eenen brief van Anquetil du Perron, welke door A. G. Camper in 1790 over de beteekenis en aard dier boeken geraadpleegd was en hem met een uitvoerig antwoord gediend had, welke brief na den dood van H. A. Hamaker in mijn bezit gekomen was, aan den toenmaligen Bibliothecaris W. G. Pluygers getoond. Pluygers heeft eigenhandig daaruit afgeschreven, wat op de koperen boeken betrekking had, maar wat de brief meer bevatte weggelaten, en daarvoor alleen etc. etc. etc., benevens het slot van den brief met de handteekening van Anquetil gegeven. Ook heeft hij daarbij eenige aanwijzingen gevoegd, die ik hem toen mondeling gegeven had. Dit eigenhandig door P. geschreven stuk is bij de boeken nedergelegd, en door Houtsma gevonden en uitgegeven. Het adres, waarin de brief van Anquetil bewaard is, is zooals Pluygers reeds opmerkte, niet van de hand van Anquetil. A. G. Camper had dien brief aan eenen vriend of geleerde ter lezing gezonden en deze zond hem terug met het adres:

\section{Monsieur A. G. CAMPER, \\ à Klein-Lankum.}

Klein-Lankum is niet een gehucht, maar de naam der buitenplaats van de Campers, die na den dood van A. G. C. gesloopt is.

De schenking der boeken heeft voor bijna dertig jaren plaats gehad en toen ik den brief van Anquetil aan Dr. Kern vertoonde, was het mij ontgaan dat ik daarover met den Bibliothecaris W. G. Pluygers gesproken had." w. g. H. G. HAMAKER.

Voor het begin van den brief van Anquetil verwijs ik naar de mededeeling van Houtsma in de Bijdragen; het vervolg luidt aldus: "Maintenant permettez-moi, Monsieur, de vous faire connoître un trésor que posséde votre pays: en $1875 \mathrm{~m}$. P. Van Eyk, Précepteur de l'Ecole latine à Bois-le-Duc, in de Hinthamerstraat, me fit l'honneur de m'écrire, pour me consulter sur un Manuscrit qu'un Capitaine de la Marine, demeurant dans cette ville, lui avoit communiqué. Sa lettre contenoit les premieres lignes de l'ouvrage. Je lui répondis sur le champ que c'étoit le Vendidad sadé, que les lignes étoient du Zend, du Pehlvi, du Persan et je lui en donnai l'explication, en l'engageant à porter ce Capitaine à le présenter aux États-Généraux et à le déposer ensuite à la Bibliothèque de Leyde. J'ajoutois qu'il n'y avoit eu jusqu'alors que deux exemplaires de connus de cet ouvrage, regardé à Surate comme le morceau principal de la Liturgie des Parses: le premier, à Oxford; le 2e, à lá Bibli- 
othèque du Roi à Paris; que celui du Capitaine de Marine, faisant le troisième, méritoit d'être déposé dans une Bibliothèque aussi célèbre que celle de Leyde; et que j'étois charmé, de pouvoir reconnoitre à cette occasion, les obligations que j'avois à la Nation hollandaise pour le succès de mes recherches dans l'Inde. Je ne sais si ma lettre a été remise à M. Van Eyk. Je n'en ai pas, depuis, entendu parler. Un homme de votre mérite ne négligera pas cette indication. La race des bons écrivains est éteinte, à Surate: un Vendidad sudé, copié avant mon arrivée dans l'Inde, est un trésor digne d'être placé dans un dépot public.

Trouvez hon, Monsieur, que je vous demande, si la chose dépend de vous, un petit service. En $1778, \mathrm{~m}$. Rey a imprimé à Amsterdam ma Législation Orientale; $\mathrm{m}$. Bernoulli s'est chargé de faire paraitre à Berlin mes Recherches sur l'Inde; l'ouvrage a fini d'être imprimé en 1788. Nos libraires, à Paris, montent la garde, vont au District, font d'exercice. On n'imprime plus que les Pamphlets du moment. Pouviez-vous m'indiquer en Hollande un librairie intelligent, qui voulût se charger de deux ouvrages auxquels j'ai mis la dernière main? je suis dans l'usage de donner mon manuscrit gratis; J'imprimeur, s'il le juge à propos, me gratifie de 25 exemplaires, pour mes parents et mes amis.

Le $1^{\mathbf{r}}$ ouvrage a pour titre:

L'Inde en rapport avec l'Europe: Ouvrage dans lequel on développe les intérets Politiques de CInde, la Nature de son Commerce, et où lon présente un Plan d̂Administration également utile à cetle contrée et à l'Europe. 2 Vol. en 80.

Le 2e ovrage est TOupnek'hat, traduit du Persan, mélé de Samskrétam. 2 vol. en 4.0.

Ce dernier morceau présente le Systême de la Philosophie Indienne, tirée des 4 Vedes.

Vous voyez, Monsieur, que le premier ouvrage est politique; le second, littéraire. Comme je conserve toujours pour l'Inde un intérêt vif, je tâche de faire marcher ces deux objets de front. $\mathrm{Si}$ vous trouvez le libraire que je cherche, je ferai sur le champ une copie du premier ouvrage, et tandis qu'on l'imprimera, j'ajouterai au second de longues nofes tirées du Mahabarat (manuscrit Persan de 1600 pages en fol. qui contient toute l'Inde ancienne, historique, physique et morale) et d'autres ouvrages.

Pour éviter les rétards, je vous prie, Monsieur, de vouloir bien m'adresser votre réponse immédiatement, avec un mot du libraire 
qui aura accepté mes ouvrages. Vous savez que leur objet est toujours le bien général. Lues hommes de tout pays, peuvent réaliser ou rectifier les observations que me fournissent mes lectures, mes réflexions.

Votre lettre est une vraie consolation, un calmant efficace au milieu des troubles où nous vivons. Je ne vois absolument personne, continuant toujours mes travaux. Vous sentez si je puis converser avec des hommes qui disent et écrivent avec des bayonnettes, que le genre humain date de 1790. Quand l'ordre, l'autorité légitime sera rétablie, j'aurai au moins la satisfaction d'avoir perdu le moins de tems possible, quoi qu'on n'ait guere sa tête à soi.

Je vous prie, d'agréer mes voeux sincères, pour tout cequi peut vous être agréable, et d'être persuadé que personne n'êst avec des sentimens plus vifs, avec plus de considérations que moi, Monsieur,

Votre très Humble et très Obéissant Serviteur, Anquetrl du Perron de l'Acad. des Belles Lettres. à Paris. Chaussée d'Antin. № 21. 